\title{
CORPOS ESTRANHOS \\ NA POESIA BRASILEIRA \\ CONTEMPORÂNEA: ADENIZE \\ FRANCO, PRESENTE!
}

Elizandra Alves ${ }^{1}$

Adenize Aparecida Franco ${ }^{2}$

\begin{abstract}
Resumo: Os poemas "mulher depois" e "para laura”, respectivamente de Angélica Freitas e Adelaide Ivánova, servem-nos de análise para a discussão da representação das identidades de gênero e violência que tematizam os textos. Eles tomam como figura central as minorias sexuais (transexual, homossexual e travesti) e, de maneira estética e política, discutem a representação dessas identidades e orientações. De fortes traços combativos, portanto, os poemas em estudo sinalizam para a discussão da corporeidade enquanto espaço de enfrentamento, empoderamento e resistência. Com base nos estudos teóricos de Louro (2016, 2018) e Butler (2018), entre outros, procura-se estabelecer uma análise dos poemas destacados como forma de discussão acerca da representatividade desses corpos estranhos, os lugares que ocupam e a necessidade de romper o silenciamento ao qual foram impostos na sociedade.
\end{abstract}

Palavras-chave: corpo; performatividade; Adelaide Ivánova; Angélica Freitas; poesia contemporânea brasileira

\section{STRANGE BODIES IN CONTEMPORARY BRAZILIAN POETRY: ADENIZE FRANCO, PRESENT!}

\begin{abstract}
The poems "mulher depois" and "para laura", by Angélica Freitas and Adelaide Ivánova, respectively, serve as an analysis for the discussion of the representation of gender and violence identities that thematize them. They take sexual minorities (transsexual, homosexual and transvestite) as their central figures and, in an aesthetic and political way, discuss the representation of these identities and orientations. With strong combative traits, therefore, the poems under study signal for the discussion of corporeality as a space for confrontation, empowerment and resistance. Based on the theoretical studies of Louro $(2016,2018)$ and Butler (2015), among otheres, we make an attempt to establish an analysis of the highlighted poems as a way of discussion about the representativeness of these strange bodies, the places they occupy and the need to break the silence that was imposed to them on society.
\end{abstract}

Keywords: body; performativity; Adelaide Ivánova; Angélica Freitas; contemporary Brazilian poetry

1 Doutoranda em Estudos Literários (UEM) e professor do Departamento de Letras, Guarapuava. E-mail ealves@unicentro. br

2 Doutora em Letras (USP), professora do DELET e PPGL (in memorian) 


\section{Amigos mortos}

Hoje lembrei-me de meus amigos mortos

Passou por mim uma sensação de não mais

Um perfume que evaporou do frasco

Um livro cuja leitura ficou inacabada

Uma fruta pela metade que apodreceu na geladeira

Uma carta que chegou depois da hora

Um chá que esfriou na xícara preferida

Um filme cuja exibição restou a nenhum expectador Uma sopa na qual se formou uma película de gordura Um poema que restou incompleto no fundo da gaveta naftalítica

Hoje lembrei-me de meus amigos mortos

Num vagão do metrô lotado

Na passarela vazia

No restaurante cheio

$\mathrm{Na}$ rua sombria

No ponto de ônibus lotado

No apartamento úmido

Em minha vida tímida

Hoje lembrei-me de meus amigos mortos

Nos solitários túmulos que guardam sua casa arruinada

Nas flores que encobrem suas tristes lápides

Nas cinzas carregadas pelo vento revolto

Nas ervas daninhas que acalentam as paredes de seus mausoléus

Na névoa fria que acoberta suas tumbas

Hoje lembrei-me de meus amigos mortos

Hoje lembrei-me de meus amigos mortos

Hoje lembrei-me de meus amigos mortos

Adenize Franco ${ }^{3}$ (s/d)

\section{Angélica Freitas e Adelaide Ivánova: corpos que fazem poesia}

Este artigo detém-se na análise de dois poemas produzidos pelas brasileiras Angélica Freitas e Adelaide Ivánova, autoras de obras poéticas significativas no contexto contemporâneo. Entre tais, destacamos Um útero é do tamanho de um punho (Angélica Freitas, 2013) e O Martelo (Adelaide Ivánova, 2017), que apresentam poemas cujos elementos fundamentais tratam de questões feministas, políticas e estéticas. $\mathrm{Na}$ linha de frente de um grupo de poetas que tem colocado a arte a serviço da desconstrução de paradigmas sociais instituídos, as autoras e as obras em estudo tematizam a potencialidade da poesia em relação às questões da atual política que as envolve. A potencialidade dessa perspectiva, como se verifica, pode ser entendida como "arma" para o empoderamento do corpo das minorias sexuais e voz de resistência a partir da literatura.

Os poemas intitulados "mulher depois" e "para laura", das respectivas obras, servem-nos de análise para a discussão da representação das identidades de gênero e violência que tematizam os textos. Ambos poemas tomam como figura central as minorias sexuais (transexual, homossexual e travesti) e, de maneira estética e política, discutem a representação dessas identidades e orientações. De fortes traços combativos, portanto, os poemas em estudo sinalizam para a discussão da corporeidade enquanto espaço de enfrentamento, empoderamento e resistência. Com base nos estudos teóricos de Louro (2016, 2018) e Butler (2015), entre outros, procura-se estabelecer uma análise dos poemas destacados como forma de discussão acerca da representatividade desses corpos estranhos, os lugares que ocupam e a

3 Arquivo pessoal 
necessidade de romper o silenciamento ao qual foram impostos na sociedade.

Representante da recente geração de poetas brasileiros, Angélica Freitas tem se tornado uma das principais vozes femininas na atual literatura do Brasil. A escritora, nascida em Pelotas, Rio Grande do Sul, em 1973, publicou os livros de poemas Rilke Shake (2006) ("Não escrevi o livro com a consciência de que estava fazendo poesia com humor. Acho que para mim isso é uma maneira natural de escrever e de lidar com algumas coisas do mundo." [FREITAS, 2018, s/p]) e Um útero é do tamanho de um punbo (2013), a narrativa gráfica Guadalupe (2012), em parceria com o quadrinista Odyr, além de editar a extinta revista de poesia Modo de usar \& Co. Em 2020 publica mais um livro, Canções de Atormentar, em que traz poemas com o mesmo tom afiado que lhe é característico e a consagrou como um dos nomes mais originais da poesia brasileira contemporânea.

O poema que se apresenta para análise, "mulher depois", integra a segunda obra da autora, Um útero é do tamanho de um punho, vencedor do prêmio da Associação Paulista de Críticos de Arte em 2012. Trata-se de uma obra que revela marcas de uma escrita potente e uma voz poética que retoma a linhagem dos poetas "antipoesia". Ou seja, o poema é tomado como força de luta e combate frente às instâncias moralizantes e determinantes. Sobre o livro, até então seu grande sucesso, Angélica Freitas, em conversa mediada pelo jornalista Omar Godoy, em setembro de 2018, para o projeto Um Escritor na Biblioteca, posteriormente publicada no Jornal da Biblioteca Pública do Paraná, Cândido, diz que

[...] Queria escrever sobre algum assunto importante para mim. E a coisa da mulher sempre foi um assunto para mim, por eu ser do interior do Rio Grande do Sul, por eu ser lésbica, por eu ter consciência disso desde muito pequena e por eu nunca ter me encaixado no modelo de mulher que era esperado, sempre me senti muito esquisita e questionava isso. Será que sou menos mulher porque não uso maquiagem, porque não uso saia? Mas o que é ser mulher, afinal?" Aí decidi que eu ia embarcar nesse tema. [...]. (s/p).

Ao apresentar a autora, Godoy (2018, s/p) assinala que,

Conhecida por praticar uma literatura comprometida com causas do feminismo, Angélica, no entanto, não vê como uma obrigação o posicionamento político do artista. Para ela, "cada um sabe o que consegue fazer. Acho que ativismo político é muito importante e algumas pessoas fazem isso melhor do que outras.

Ao final da entrevista, Angélica de Freitas, no entanto, faz uma autoanálise e reconhece que sua obra está intrinsicamente ligada à política, e daí a concepção antipoética que damos aos seus poemas:

[...] Sou uma pessoa bastante retraída, como
eu disse, a coisa de me expor nunca me agradou
muito, mas essa coisa de ser mulher é política, então
não tinha como escrever sobre ser mulher, sem cair
nisso. Ao mesmo tempo, não acho que seja
uma coisa ostensivamente política, a gente até
poderia pensar no que é um poema político,
mas a questão de ser mulher e dos requisitos que a
gente tem que cumprir para ser mulher, é uma coisa
bastante política. (2018, s/p, itálicos nossos).

Esse ser político que é desvendando nos poemas de Freitas pode ser também observado em outra vOz recente da poesia brasileira, Adelaide Ivánova. Dividindo-se entre atividades no Brasil e na Alemanha, nascida no Recife, em 1982, a poeta - também jornalista, tradutora e fotógrafa desenvolve várias práticas voltadas para a literatura e as artes fotográficas. Sua produção artística surge publicada em 2014 com Autonomia e Polaróides, e o livro de poemas O Martelo, publicado no Brasil em 2017. Essa última rendeu-lhe indicações a vários prêmios e a fez receber críticas significativas. Silveira apresenta a obra como

[...] um conjunto de poemas que traz para a frente do palco, ao primeiro plano das escolhas formais e da matéria fundamental de cada texto - o estupro, o silenciamento feminino, o desprezo misógino - os mil modos, enfim, da violência que se pratica diariamente contra 
as mulheres no Brasil e além. [...] (2017, s/p).

Os escritos de Ivánova clamam pela abertura urgente da Caixa de Pandora que são os não-ditos, sistematicamente ignorado em muitos governos, do universo feminino, como relações abusivas, estupros, violência de gênero, citando alguns. Há de ser ter coragem para tal posicionamento político, já que a autora, em entrevista a Schneider Carpeggiani, publicada no Suplemento Pernambuco, em fevereiro de 2016, faz mea-culpa sobre ser feminista:

\begin{abstract}
Não é minha obra que é feminista, eu sou feminista e tudo o que eu fizer vai ser também - ao menos é a isso que en aspiro. Eu destaco isso porque mais importante que uma obra feminista é levar uma vida que se posicione e isso é tão difícil. Eu vivo num relacionamento heterossexual burguês e sou diariamente confrontada com limitações à minha liberdade intelectual, sexual, emocional - tanto pelo meu marido, quanto pelas nossas famílias, pela sociedade e principalmente por mim mesma. E preciso estar atento pra conseguir ser socialmente funcional e, ao mesmo tempo, se manter ativista. Rihanna, Beyoncé e Madonna, por exemplo, todas são feministas e lutam pelo empoderamento das mulheres, mas cometeram deslizes graves em suas vidas pessoais, no que diz respeito a casos de violência e/ou machismo. Então sim, o livro é feminista porque minha vida é. Mas a obra não basta. (s/p, aspas nossas).
\end{abstract}

"Voz que vem do futuro, poesia por vir [...]. Poesia contra polícia, desestabilizadora dos discursos do poder [...].”, como destaca Carpeggiani (2016, s/p), também entendemos Adelaide Ivánova como detentora de um fazer antipoético, por estabelecer em seus poemas uma forte crítica combativa aos modos de violência que atingem os corpos femininos na sociedade brasileira. Assim, ela inscreve-se ao lado de Angélica Freitas enquanto autoras que marcam seus textos com discussões acerca do corpo enquanto espaço de enfrentamento à uma política de silenciamento de corpos que significam.

\section{De úteros e martelos: o corpo da palavra}

Nominadas com palavras fortes já em seus títulos, as obras em estudo trazem à tona o corpo feminino. Em Um útero é do tamanho de um punho, Angélica Freitas parte de um órgão feminino, o útero, que historicamente carrega toda a relação corporal que se estabelece com o ser feminino, ser mulher, e associa-o a outra parte corporal, que é o punho. Segundo a autora, um útero teria o tamanho de um punho fechado: “[...] É uma frase que li na internet há uns quatro anos, quando estava pesquisando textos sobre o corpo da mulher. Encontrei um que lá pelas tantas dizia: 'um útero é do tamanho de um punho fechado'. [...]" (FREITAS, 2012, s/p). O punho cerrado é marca da forma que a posição da mão carrega para a luta. Ou ainda, o símbolo característico da luta feminista.

Não é de outra forma que a escolha do título O martelo, para a obra de Adelaide Ivánova, se justifica. Em entrevista, a autora confessou que dormia com um martelo embaixo do travesseiro “[...] Então o livro nasceu por causa desse objeto muito concreto, mas que também tem, claro, a simbologia que ele adquire quando deslocado do lugar ao qual ele pertence (a caixa de ferramenta haha). Então não tem alegoria, é a vida mesmo. [...]" (IVÁNOVA, 2016, s/p). O martelo, objeto, intitula a obra e o primeiro poema que abre o livro. Nesse poema, a autora expressa a relação entre o objeto e a violência que ele pode desencadear: o mesmo martelo que ataca é usado para se defender. De certa forma, a ideia desenvolve-se no decorrer do livro para as questões, também, do martelo da lei e da justiça. Dentro desse universo da linguagem, cabe destacar que violência e justiça são relacionadas ao corpo e à mulher. Em seu poema “o urubu”, destaca-se a menção à definição de “corpo de delito" e as relações de violência que 
são estabelecidas a partir de um corpo enquanto espaço/lugar de infração. No caso do poema, duas vezes, primeiro pela violência física vivenciada que leva esse corpo feminino ao hospital e, em segundo, violência pelos próprios médicos que tratam o exame de corpo de delito com displicência. "[...] e decidindo diante de minhas pernas/abertas se depois do/expediente iam todos pro bar [...]" ou "o doutor é uma pessoa/lida com mortos e mulheres vivas/ (que ele chama de peças)/com coisas." (IVÁNOVA, 2017, p. 25, $18^{\circ}, 19^{\circ}, 20^{\circ}, 28^{\circ}$, $29^{\circ}, 30^{\circ}$ e $31^{\circ}$ versos). Os últimos versos do poema destacam a forma como as mulheres e seus corpos são tratados nos mais variados espaços sociais: coisas.

As obras, como já observamos, detêm-se sobre a discussão das mulheres, dos corpos e ao que é negado a essas subjetividades. Como assinala Guacira Lopes Louro, em O Corpo Educado,

\begin{abstract}
As muitas formas de fazer-se mulher ou homem, as várias possibilidades de viver prazeres e desejos corporais são sempre sugeridas, anunciadas, promovidas socialmente (e hoje possivelmente de formas mais explícitas do que antes). Elas são também, renovadamente, reguladas, condenadas ou negadas. [...]. (2018, p. 10).
\end{abstract}

Diante desse processo, as obras de Angélica Freitas e Adelaide Ivánova surgem como possibilidades de questionamentos frente a tais funcionamentos de poderes instituídos.

Podemos começar a refletir sobre isso a partir da organização das obras e seus poemas. Um útero é do tamanho de um punho é composto por 36 poemas divididos em sete sessões, Uma mulher limpa, Mulher de, A mulher é uma construção, Um útero é do tamanho de um punho, 3 poemas com auxílio do google, Argentina e $\mathbf{O}$ livro rosa do coração dos trouxas, e algumas constituemse de um grupo de poemas e outra em que há apenas um poema longo, como é o caso do poema homônimo à obra. Como é possível observar pelos títulos, os poemas configuram-se pela temática feminina e inscritos no que mencionamos como "antipoesia" em que, marcados pela tônica da crítica feroz a partir de recursos como o sarcasmo, a ironia, o não-dito, reverberam a luta pelo empoderamento feminino.

O Martelo é dividida em duas partes, respectivamente um (I) e dois (II). Nelas inscrevem-se poemas que também, endossam a temática do feminino associada às situações de violência descritas de forma irônica, sarcástica e agressiva. Temas como estupro, aborto, violências das mais variadas formas em relação ao corpo feminino e, ainda, negligenciadas pelos poderes jurídicos ou sociais, conduzem o ritmo dos poemas. Nas palavras da autora,

\begin{abstract}
O marteloé um livro sobre violência e sexualidade feminina, narrado por uma voz feminina sem nome, com um antagonista (o príncipe) e um herói ambivalente (Humboldt). O livro é assim dividido em duas partes - na primeira, a mulher sem nome descreve sua experiência pós-estupro dentro de instituições públicas e instâncias burocráticas; na segunda parte, ela descreve sua experiência como mulher casada e adúltera, fazendo paralelos questionáveis e suspeitos entre marido e amante, e entre estupro e sexo consensual. A divisão do livro é inspirada por Constantino, o Grande, primeiro imperador romano cristão, que criou uma lei estabelecendo que o estupro e o adultério eram crimes semelhantes, cometidos apenas pela mulher, por ela ser incapaz de cuidar da propriedade de seu marido (por exemplo: seu $\left.\operatorname{corpo}^{4}\right)$. (IVÁNOVA, s/d, s/p, tradução nossa).
\end{abstract}

4 o martelo is a book about violence and female sexuality, narrated by a nameless female voice, with an antagonist (the prince) and a ambivalent hero (Humboldt). The book is thus divided in two parts - in the first one, the nameless woman describes her post-rape experience within public institutions and bureaucratic instances; in the second part, she describes her experience as both married and adulterous woman, making questionable, suspicious parallels between husband and lover, and between rape and consensual sex. The division of the book is inspired by Constantine the Great, the first Christian Roman emperor, who created a law establishing that rape and adultery were similar crimes, committed only by the woman, for her being unable to take care of her husband's property (i.e. her body). 


\section{Os corpos trans no/do poema}

Para as discussões do tema proposto selecionamos os poemas "mulher depois" e "para laura”, integrantes da sessão Mulher de, de Um útero é do tamanho de um punho, e da primeira parte de O Martelo, respectivamente. Ambos abordam a temática do corpo queer, em suas expressões corpóreas da mulher transexual e da mulher travesti. Tomamos a referência ao termo queer considerando a afirmação de Guacira Lopes Louro, em Um corpo estranho (2016, p. 08, itálico nosso), de que “[...] Queer é um corpo estranho, que incomoda, perturba, provoca e fascina". Esses quatro verbos se inclinam sobre esses corpos representativos nos poemas das duas autoras em destaque. Inscritos em obras que discutem o corpo, em especial o corpo feminino, os poemas se solidificam na luta pela necessidade de não serem mais negligenciados ou não visibilizados socialmente. São corpos sempre conduzidos à ideia de incomodo, que perturbam a heteronormatividade, que provocam inquietações a ponto de serem retirados violentamente da sociedade5 e que fascinam por sua sexualidade desviante, ex-cêntrica6.

Iniciaremos com a análise e discussão do poema de Angélica Freitas:

\section{mulher depois}

queridos pai e mãe
tô escrevendo da tailândia
é um país fascinante
tem até elefante
e umas praias bem bacanas

mas tô aqui por outras coisas

embora adore fazer turismo

5 Segundo a ANTRA (Associação Nacional de Travestis e Transexuais), o mapa de pessoas trans confirmou informações de 124 assassinatos no ano de 2019.

6 O Brasil é um dos países que mais procura e consome pornografia cujas identidades trans e travestis sejam destaque. pai, lembra quando você dizia que eu parecia uma guria e a mãe pedia: deixem disso?

pois agora eu virei mulher me operei e virei mulher não precisa me aceitar não precisa nem me olhar mas agora eu sou mulher

(FREITAS, 2013, p. 35)

O poema "mulher depois", como já citado, se inscreve na segunda sessão da obra de Angélica Freitas. Agrupado a poemas que são marcados por alguma caracterização ("mulher de vermelho", "mulher de valores", "mulher de posses", "mulher depressa", "mulher de um homem só", citando alguns títulos), o poema é nomeado pela temática principal da obra, mulher, substantivo adicionado ao advérbio depois. A compreensão da preposição de que se transforma no advérbio depois é um dado interessante (ainda que a palavra, também, possa ser considerada preposição). Esse processo de transformação da palavra, em sua mudança de categoria gramatical já nos provoca em relação ao tema desenvolvido no poema sobre a questão transexual. Esse processo de transformação do sujeito no poema pode ser compreendido dentro das considerações de Louro (2016) a partir da metáfora da viagem. Em seu capítulo Viajantes pós-modernos, considerando tal pensamento, a autora afirma que "a viagem transforma o corpo, o "caráter", a identidade, o modo de ser e de estar... [...] As mudanças de viagem podem afetar corpo e identidades em dimensões aparentemente definidas e decididas desde o nascimento (ou até antes dele)" (itálicos nossos, aspas originais, p. 15).

Dividido em três estrofes de cinco versos, o poema revela, na primeira, o esboço de uma carta de alguém distante, iniciando pela saudação 
aos destinatários, "queridos pai e mãe" (2013, p. $35,1^{\circ}$ verso). Na sequência, o local de onde esse remetente escreve, "tô escrevendo da tailândia" (2013, p. 35, $2^{\circ}$ verso) e as características do país (é fascinante, tem elefantes e praias bacanas). Desse modo, percebemos a ideia de viagem que irá atravessar o poema. Como sabemos, a viagem inscreve-se, também, na ideia de deslocamento - por isso, a utilização do termo como metáfora para Louro (2016), deslocamento não somente de espaço ou tempo, mas ainda do próprio sujeito. Como a autora afirma, "[...] não há corpo que não seja, desde sempre, dito e feito na cultura; descrito, nomeado e reconhecido na linguagem, através dos signos, dos dispositivos, das convenções e das tecnologias.” (LOURO, 2016, p.84). No caso do poema, o deslocamento se dará tanto na transição do espaço - do Brasil para a Tailândia - quanto na transição do corpo - de homem para mulher. Entretanto, nem um nem outro, Brasil e homem, são evidenciados pela palavra, mas compreensíveis pelo não-dito. Assim, a primeira estrofe nos coloca diante do que será significativo dessa viagem que será a mudança que afetará o corpo e alterará sua dimensão. Isso porque é sabido que a Tailândia, país do sudeste asiático, é conhecida como o lugar em que mais se realizam cirurgias de redesignação sexual $^{7}$.

A justificativa para que se compreenda que a voz poética realizou a cirurgia começa a se delinear na segunda estrofe. Iniciada pela conjunção adversativa "mas", essa voz esclarece que não foi ao país asiático para fazer turismo e sim que lá está "por outras coisas" (2013, p. 35, 60 verso), outros motivos. Ao evocar um diálogo com o pai e a mãe revela: "pai, lembra quando você dizia/que eu

\footnotetext{
7 Ladyboys é o termo utilizado na Tailândia para transexuais. Lá, também, acontece o maior concurso de beleza transexual. Entretanto, Bangcoc, capital da Tailândia, é a única cidade asiática incluída nas listas de destino gay-friendly do mundo. $\mathrm{E}$, apesar de ser um país reconhecido pelas cirurgias de alta qualidade, a comunidade transexual é impedida de mudar de nome em seus documentos de identidade e, portanto, não é reconhecida legalmente.
}

parecia uma guria/e a mãe pedia: deixem disso?" (2013, p. 35, $8^{\circ}, 9^{\circ}$ e $10^{\circ}$ versos). Essa memória familiar reporta à indicação da sexualidade e da identidade. Cabe lembrar o processo de afirmação que a linguagem instaura com o dizer, conforme Butler (2018, no capítulo Corpos que pesam: sobre limites discursivos do "sexo", em O corpo educado) assinala sobre o processo de "fazer" o corpo ou feminino ou masculino.

\begin{abstract}
Estas atribuições ou interpelações alimentam aquele campo de discurso e poder que orquestra, delimita e sustenta aquilo que pode legitimamente ser descrito como "humano". Nós vemos isto mais claramente nos exemplos daqueles seres abjetos que não parecem apropriadamente generificados; é sua própria humanidade que se torna questionada. [...]. (BUTLER, p. 205, aspas originais)
\end{abstract}

O poema evidencia a relação que se estabelece no processo da linguagem e de sua interpelação. Se o pai verbalizava a frase "parecia uma guria" - guria enquanto termo regional gaúcho para designar o sujeito do sexo feminino - pressupomos que a voz lírica não fosse uma menina e sim um menino e que, por sua vez, por características consideradas do sexo feminino, assemelhava-se a uma menina. Ideia corroborada pelo pedido da mãe. Reiterando o entendimento de Butler no fragmento acima, a construção do gênero, por ser excludente, apaga a articulação cultural em detrimento da lógica que "[...] supõe o sexo como um "dado" anterior à cultura e lhe atribui um caráter imutável, a-histórico e binário. [...]" (LOURO, 2016, p. 15).

Justamente por não possuir um caráter imutável é que compreendemos a terceira estrofe como a designação desse corpo estranho que agora, também pela linguagem, se apropria de suas certezas. Estrofe que se inicia com uma conjunção conclusiva, deduzimos por se tratar do fechamento do poema, que assume, no momento presente "agora", sua identidade feminina. Os $11^{\circ}$ e $12^{\circ}$ versos, "eu virei mulher/me operei e virei mulher", evidenciam o trajeto do corpo, do masculino ao 
feminino, pela cirurgia de redesignação sexual, afirmada pelo verbo "operar". Ciente das negativas de aceitação, "não precisa me aceitar/não precisa nem me olhar", o corpo se afirma como feminino, "mas agora eu sou mulher" (FREITAS, 2013, p. $35,13^{\circ}, 14^{\circ}$ e $15^{\circ}$ versos). Entre o parecer e o ser, verbos enunciados na $2^{\mathrm{a}}$ e $3^{\mathrm{a}}$ estrofes, há o trânsito para a consolidação do gênero feminino desse corpo transexual e, portanto, muitas vezes não legitimado.

O processo de afirmação indicado no último verso denota a performatividade desse corpo estranho. Como afirma Butler (2018, p. 213), “[...] na teoria do ato da fala, um ato performativo é aquela prática discursiva que efetua ou produz aquilo que ela nomeia", sem esquecer que o ato performativo está atrelado à “[...] prática forçosa e reiterativa dos regimes sexuais regulatórios [...]" (p. 218.), uma vez que, marcado pelo uso do advérbio temporal "agora", a voz lírica se autoriza a falar seu gênero. Enquanto o poema como um todo, por usar elementos característicos de uma carta, destina-se a "assumir" a existência de um corpo transexual. Nisso demonstrando ser um corpo estranho uma vez que vivemos numa sociedade em que há todo "um trabalho pedagógico contínuo, repetitivo e interminável [...]” colocado em prática “[...] para inscrever nos corpos o gênero e a sexualidade 'legítimos"' (LOURO, 2016, p. 17, aspas originais), ou seja, o corpo não legitimado pela ordem compulsória heterossexual e heteronormativa inscreve-se dentro da marginalidade.

O título do poema é significativo, portanto, desse processo de transição e do lugar que ocupa esse corpo. É no “depois" - depois da viagem, depois da cirurgia de redesignação, depois da escrita da carta - que o corpo se afirma como feminino, como mulher. Além, evidentemente, de estar marcado pela complementaridade que vem a partir do "depois". Depois de passar uma vida ocupando um corpo "errado", esse corpo consegue, finalmente, se reconhecer por completo. Butler, em entrevista a Irene Meijer e Baukje Prins, em 1996, afirma que nos discursos "[...] habitam corpos [...]", que "eles se acomodam em corpos [...]" ou, ainda, de forma mais enfática, que "[...] os corpos, na verdade carregam discursos como parte de seu próprio sangue" (2002, s/p).

Passamos, agora, à análise do poema de Adelaide Ivánova, pertencente à primeira parte do livro $O$ martelo. Junto a demais poemas que tematizam violências contra as mulheres e a temática geradora do estupro, "para laura" descreve o assassinato de dois corpos estranhos, dois corpos que fogem da normativa determinante em nossa sociedade. $\mathrm{O}$ poema intitula-se em tom de dedicatória, ou seja, podemos entrever que o poema, em seu título, é dedicado a alguém nominado de Laura. As dedicatórias são feitas para alguém, seja em livros ou em trabalhos científicos. Em outras situações, as dedicatórias são feitas para alguém que já se foi, que não está mais vivo. É nesse caso que se caracteriza o poema de Adelaide Ivánova. Quem é Laura? Quem é laura, minusculizada? Êi-la:

\section{para laura}

em 1998 quando encontraram o corpo gay de matthew shepard

sua cara tinha sangue por todo lado

menos duas listras

perpendiculares

que era por onde suas lágrimas

haviam escorrido

naquele dia o ciclista

que o encontrou não

ligou para polícia logo que o viu porque o corpo de matthew

estava tão deformado

que o ciclista achou ter visto 
um espantalho

sábado passado em são paulo

a polícia matou laura

não sem antes

torturá-la laura

foi filmada ainda viva

por outro sujeito

que em vez de ajudá-la

postou no youtube o vídeo

d'uma laura desorientada

e quem não estaria

tendo sangue na boca e na parte

de trás do vestido

laura tem um corpo

e um nome que lhe pertencem

laura de vermont presente!

foi assassinada pela nossa indiferença

e pela polícia brasileira

tinha 18 anos

(IVÁNOVA, 2017, p.17)

Dividido em três estrofes, o poema evoca os corpos de Matthew Shepard e Laura de Vermont. Todo o poema é marcado pelo uso de minúsculas, como o de Angélica Freitas, inclusive os nomes próprios, indicando, de certa forma, a impropriedade dos sujeitos, conduzindo à compreensão de sua não importância existencial. Substantivos comuns. Coisas.

A primeira estrofe detém-se num período temporal, 1998, quando da morte violenta do estudante norte-americano Matthew Shepard (1976-1998). O rapaz, de 21 anos, foi torturado e assassinado em Wyoming e morreu vítima de traumatismo craniano. A morte de Shepard foi considerada um crime homofóbico cuja repercussão e discussão nos Estados Unidos e na mídia internacional acerca dos crimes movidos por ódio levou, em 2009, o então presidente Barack Obama a aprovar a lei Matthew Shepard e James Byrd pela Prevenção de Crimes de Ódio. Marcada pela referência ao "corpo gay" de Shepard, "o corpo de matthew/ estava tão deformado/ que o ciclista achou ter visto/um espantalho" (IVÁNOVA, 2017, p. $17,11^{\circ}, 12^{\circ}, 13^{\circ}$ e $14^{\circ}$ versos), essa estrofe inicial metaforiza o modo como o corpo do rapaz foi encontrado. Segundo notícias da época, Shepard foi violentamente atacado e preso a uma cerca em meio a um campo rural. Lá foi encontrado dias depois. Os versos de Ivánova evocam a relação entre o corpo desfigurado (deformado) de Shepard com os espantalhos, bonecos feitos de palha ou outros materiais que simulam um ser humano e são utilizados em plantações para espantar aves ou outros animais.

A segunda estrofe detém-se num tempo atualizado, num espaço referencial específico, “sábado passado em são paulo" (IVÁNOVA, 2017, p. $15^{\circ}$ verso), e traz à tona o corpo torturado de Laura, que fora referenciado no título. Segundo o poema, o corpo de Laura foi torturado e morto pela polícia, filmado e postado no YouTube por uma terceira pessoa e no vídeo a exposição do corpo violentado e sangrado da jovem. A referência estabelece relação, como veremos, com o nome completo de Laura na terceira estrofe, a Laura de Vermont.

Travesti, de 18 anos, Laura foi morta a socos e pauladas na zona leste de São Paulo em junho de 2015. Atacada por cinco homens, a travesti morreu de traumatismo craniano. Um vídeo foi gravado e postado no YouTube em que aparece Laura pedindo socorro enquanto caminha ensanguentada. As investigações apontaram que, depois de ser atacada e violentada, Laura entrou num carro policial em que foi atingida por uma bala que atravessou seu braço $^{8}$. O caso comoveu a comunidade LGBT, 8 Sobre o caso, ver https://g1.globo.com/sao-paulo/ 
entretanto, assim como ocorreu com Matthew Shepard muitas notícias tentam dissociar os crimes da motivação homofóbica ou transfóbica 9 .

A última estrofe do poema de Adelaide Ivánova expressa a indignação em relação à crueldade cometida com Laura, "laura tem um corpo/e um nome que lhe pertecem/laura de vermont presente!" (IVÁNOVA, 2017, p. 17, $27^{\circ}, 28^{\circ}$ e $29^{\circ}$ versos). O terceiro verso enfatiza a presentividade de Laura. Ao utilizar uma expressão que se tornou usual nos últimos anos e, ao que nos parece, recupera a utilizada nas escolas quando os alunos respondem à chamada do professor, o poema instaura a presença (ainda que na morte) de Laura de Vermont. A exclamação, único sinal de pontuação utilizado em todo o poema, revela a potência desse corpo que, mesmo morto, colocase em evidência. Um corpo estranho, como afirma Louro, um corpo que "[...] incomoda, perturba, provoca, fascina" (2016, p. 8). Ao fim da estrofe, associado ao não reconhecimento do corpo de Shepard e à espetacularização da violência através do vídeo em que aparece Laura, o verso sinaliza para nossa participação nos crimes, "foi assassinada pela nossa indiferença" (IVÁNOVA, 2017, p. 17, $30^{\circ}$ verso). O verso coloca nossa parcela de culpa, em especial, ao crime de Laura, afinal, as imagens do repugnante também podem ser sedutoras e colocar nosso descaso e nossa indiferença quando partilhamos desse espetáculo propagado em redes sociais ou aplicativos de conversa.

noticia/apos-2-anos-5-reus-acusados-de-matar-travestilaura-vermont-seguem-soltos.ghtml. Acesso em 30 de agosto de 2020 .

9 Sobre Matthew Shepard, algumas matérias de investigação jornalística própria, pesou a acusação dele ter sido traficante de drogas e, por isso, ter sido morto por um dos acusados, enquanto, possivelmente, teria tido um relacionamento com outro. Quanto à travesti Laura de Vermont, pesa a acusação de que ela teria iniciado a discussão com o grupo de rapazes que a atacou, assim como ter tentado roubar o carro da polícia que foi até o local responder ao chamado. Parece que há uma nítida tentativa dos meios mídiacos em desfavorecer os fatos. Ainda que pese sobre os corpos mortos atos de responsabilização, ambos foram mortos de forma vil, violenta e tortuosa.
O poema "para laura" inscreve os corpos homossexual e travesti dentro do que compreendemos aqui, a partirde Louro (2016), como corpo estranho. Ou ainda, como exemplaridades, se assim for possível, dos corpos abjetos a que se refere Butler, porque sua humanidade é questionada e apagada. Esses corpos inscritos no poema revelamse, ainda que transfigurados pelos atos de violência que os vitimou, não corpos dóceis, na acepção de Foucault, mas justamente corpos que são hostilizados, que são preteridos e, especialmente, retirados de circulação. Como afirma Foucault, em entrevista de 1975, intitulada Poder-Corpo, "O corpo se tornou aquilo que está em jogo numa luta entre os filhos e os pais, entre a criança e as instâncias de controle" (1996, p. 147), ou seja, estamos falando de relações de poder que engendram os caminhos da corporeidade.

Os corpos de Matthew e Laura no corpo do poema de Ivánova tornam-se exemplares de que mesmo vitimados pela violência, gerada dentro de um sistema agressivo e repressor, apresentamse para a luta, para o combate. Adelaide Ivánova em performance intitulada mimimi, para a séria "Fruto estranho", apresentada na FLIP 2017, cita o poema "sobre uma foto no huffington post, em 01 de novembro de 2015”, cujo final assinala “já/ se sabe que poemas tal qual leis não mudam nada tudo/ sobre isso já foi legislado e dito em todas as línguas/ também em português mas meu deus/ de que adiantaria meu silêncio?/ de quem estaria meu silêncio a serviço?” (IVÁNOVA, 2017, s/p). Entendemos que os poemas "mulher depois" e "para laura" rompem esse silêncio a que Ivánova se refere. Comparando poemas a leis, a autora confere descrença às instituições jurídicas que pesam sobre os corpos.

Nas relações de poder, justamente, aqueles que exercem em determinado momento o poder acabam por categorizar esses corpos e conduzir a "[...] um conjunto de exclusões, de apagamentos 
radicais, os quais, estritamente falando, recusam a possibilidade de articulação cultural. [...]" (BUTLER, 2018, p. 205). A palavras de Butler pesam sobremaneira na compreensão desses sujeitos/corpos referidos nos poemas. Corpos que sofrem a exclusão social por não se adequarem aos padrões normativos e, consequentemente, sofrem os "apagamentos radicais". Como formas de se contrapor ao sistema que os segrega, encontram formas de resistir, subverter essas normas regulatórias. Seja o próprio corpo, seja o corpo feito poema. Louro (2016, p. 85) referenda, “[...] em ambas as direções, é no corpo e através do corpo que os processos de afirmação ou transgressão das normas regulatórias se realizam e se expressam. Assim, os corpos são marcados social, simbólica e materialmente - pelo próprio sujeito e pelos outros. [...]”. Mas, também, é o próprio corpo espaço de enfrentamento e insubordinação a essas marcas impostas. Seus corpos enquanto poema não estão a serviço de nossa sociedade patriarcal, heteronormativa, misógina, homoléstransfóbica e, especialmente, assassina. Nenhum. O de Freitas, Ivánova, da mulher depois, de Matthew, de Laura. Presentes.

\section{Referências}

BUTLER, Judith. Corpos que pesam: sobre os limites discursivos do sexo. In LOURO, Guacira Lopes (org.). O corpo educado: pedagogias da sexualidade. Belo Horizonte: Autêntica Editora, 2018.

CARPEGGIANI, Schneider. Um livro como se fosse uma mordida. Disponível em: http:// www.suplementopernambuco.com.br/ entrevistas/1544-um-livro-como-se-fosse-umamordida.html. Acesso em 21 de agosto de 2018.

DOSSIÊ assassinatos contra travestis brasileiras e violência e transexuais em 2019. ANTRA: Associação Nacional de Travestis e Transexuais. In https://antrabrasil.files.wordpress.com/2020/01/ dossic3aa-dos-assassinatos-e-da-violc3aanciacontra-pessoas-trans-em-2019.pdf. Acesso em 30 de agosto de 2020.

FRANCO, Adenize Aparecida. "Amigos mortos". Arquivo pessoal. s/d.

FOUCAULT, Michel. Poder-Corpo. In: Microfísica do poder. Rio de Janeiro: Graal, 1996.

FREITAS, Angélica. Talvez a palavra útero incomode. https://blogdoims.com.br/author/ angelica-freitas/. Acesso em 25 de agosto de 2020.

FREITAS, Angélica. Um Escritor na Biblioteca / Angélica Freitas. In Cândido, n.o 89, Dezembro de 2018. Disponível em http://www.bpp.pr.gov. br/Candido/Pagina/Candido-No-89-Dezembrode-2018. Acesso em 24 de agosto de 2020.

FREITAS, Angélica. Um útero é do tamanho de um punho. São Paulo: Cosac Naify, 2013.

GERMANO, Felipe. Brasil é o país que mais procura por transexuais no RedTube - e o que maus comete crimes transfóbicos nas ruas. Super Interessante: Comportamento. In https://super. abril.com.br/comportamento/brasil-e-o-pais-quemais-procura-por-transexuais-no-red tube-e-oque-mais-comete-crimes-transfobicos-nas-ruas/. Acesso em 28 de agosto de 2020.

IVÁNOVA, Adelaide. O Martelo. Rio de Janeiro: Edições Garupa, 2017.

IVÁNOVA, Adelaide. o martelo. Disponível em https://adelaideivanova.com/projects/omartelo/. Acesso em 31 de agosto de 2018.

IVÁNOVA, Adelaide. mimimi. Performance para a série Fruto Estranho da Flip 2017. Disponível em https://adelaideivanovadotcom. files.wordpress. com/2017/09/mimimi_adelaide-ivanova.pdf. Acesso em 31 de agosto de 2018.

IVÁNOVA, Adelaide. Um livro como se fosse uma mordida. Entrevista. https:// www.suplementopernambuco.com.br/ entrevistas/1544-um-livro-como-se-fosse-uma- 
mordida.html. Acesso em 25 de agosto de 2020.

LOURO, Guacira Lopes. Pedagogias da sexualidade. In LOURO, Guacira Lopes (org.). O corpo educado: pedagogias da sexualidade. Belo Horizonte: Autêntica Editora, 2018.

LOURO, Guacira Lopes. Um corpo estranho: ensaio sobre sexualidade e teoria queer. Belo Horizonte: Autêntica, 2016.

PRINS, Baukje; MEIJER, Irene Costera. Como os corpos se tornam matéria: entrevista com Judith Butler. Rev. Estud. Fem., Florianópolis, v. 10, n. 1, p. 155-167, jan. 2002. Disponível em https://www.scielo.br/scielo.php?script $=$ sci_ arttext\&pid=S0104-026X2002000100009\&lng=pt $\&$ tlng=pt. Acesso em 28 de agosto de 2020.

SALVÁ, Ana. O lado obscuro do oásis transexual da Ásia. El País. In https:// brasil.elpais.com/brasil/2016/10/05/ internacional/1475681486_306885.html. Acesso em 28 de agosto de 2020.

SILVEIRA, Gustavo. Violáceo, vermelhosangue, (sobre O martelo, de Adelaide Ivánova). Disponível em https://escamandro.wordpress. com/2017/08/03/xanto-violaceo-vermelhosangue-sobre-o-martelo-de-adelaide-ivanova-porgustavo-silveira/. Acesso em 29 de agosto de 2020.

TOMAZ, Kleber. Após 2 anos, 5 réus acusados de matar travesti Laura Vermont seguem soltos. G1. In https://g1.globo.com/sao-paulo/noticia/apos2-anos-5-reus-acusados-de-matar-travesti-lauravermont-seguem-soltos.ghtml. Acesso em 29 de agosto de 2020 .

Submissão; agosto de 2020.

Aceite: outubro de 2020. 